\title{
Too Much of a Good Thing: Appropriate CTPA Use in the Diagnosis of PE
}

\author{
Jason A. Stamm, MD ${ }^{*}$, Kenneth E. Wood, DO²
}

\begin{abstract}
${ }^{1}$ Pulmonary and Critical Care Medicine, Geisinger Medical Center, Danville, Pennsylvania; ${ }^{2}$ School of Medicine and Maryland Critical Care Network, University of Maryland Medical System, University of Maryland Medical Center, R Adams Cowley Shock Trauma Center, University of Maryland, Baltimore, Maryland.
\end{abstract}

There is abundant evidence that the use of computed tomography pulmonary angiography (CTPA) is increasing in emergency departments and more patients are being diagnosed with pulmonary embolism (PE).1,2 The increasing availability and resolution of CTPA technology since the late 1990s has led some to suggest that PE is now being overdiagnosed, which is supported by decreasing PE case-fatality rates and the detection of small, subsegmental clots that do not result in any meaningful right-ventricular dysfunction. ${ }^{3,4}$ Indeed, recent guidelines allow that not all small PEs require anticoagulation therapy. ${ }^{5}$ Beyond overdiagnosis, there are potential patient-level harms associated with the liberal use of CTPA imaging, including the consequences of radiation and intravenous contrast exposure. ${ }^{4,6}$ At the societal level, excess CTPA use contributes to the growing costs of healthcare. ${ }^{2,7}$

Despite the above concerns, CTPA remains the diagnostic test of choice for PE. There are multiple approaches that are suggested to appropriately use CTPA in the workup of suspected $P E$, the most common of which is endorsed by best practice publications and combines a clinical score (eg, Well's score) with D-dimer testing, reserving CTPA for those patients with high clinical risk and/or positive D-dimer. ${ }^{8,9}$ Despite the professional recommendation, studies have shown that the use of PE diagnostic algorithms in clinical practice is suboptimal, resulting in much practice variation and contributing to the overuse of CTPA. ${ }^{10,11}$ In this issue, as a means of clarifying what measures improve adherence with recommended best practices, Deblois and colleagues ${ }^{12}$ perform a systematic review of the published interventions that have attempted to reduce CTPA imaging in the diagnosis of $P E$.

Deblois and colleagues are to be commended for summarizing what is unfortunately a very heterogeneous literature, the limitations of which precluded a formal meta-analysis. The authors report that most of the 17 reviewed studies incorporated either electronic clinical decision support (CDS; usually imbedded into a computerized physician order entry) tools or educational interventions in a retrospective, before-and-after design; only 3 studies were experimental and included a control group. Most of the studies included efficacy, with a few

*Address for correspondence and reprint requests: Jason A. Stamm, MD, Geisinger Medicine Center, Pulmonary and Critical Care Medicine, 100 North Academy Drive, Box 20-37, Danville, PA 17821; Telephone: 570-271-6389; Fax: 570-271-6021; E-mail: jastamm@geisinger.edu

Received: September 5, 2017; Accepted: September 18, 2017

2018 Society of Hospital Medicine DOI 10.12788/jhm.2901 evaluating safety. There was little available evidence regarding cost-effectiveness or barriers to implementation. The most studied approach, CDS, was associated with a decrease in the use of CTPA of between $8.3 \%$ and $25.4 \%$ along with an increase in PE diagnostic yield of between $3.3 \%$ and $4.4 \%$. Likewise, the appropriate use of CTPA (consistent with best practice recommendations) increased with CDS intervention from $18 \%$ to $19 \%$. The addition of individual performance feedback seemed to enhance the impact of CDS, although this finding was limited to one investigation. Conversely, educational interventions to improve physician adherence to best practice approaches were less effective than CDS, with only 1 study describing a significant decrease in CTPA use or increase in diagnostic yield. Although safety data were limited, in aggregate, the reported studies did not suggest any increase in mortality with interventions to reduce CTPA use.

As discussed by the authors, CDS was the most studied and most effective intervention to improve appropriate CTPA use, albeit modest in its impact. The lack of contextual details about what factors made CDS effective or not effective makes it difficult to make general recommendations. One cited study did include physician reasons for not embracing CDS, which are not surprising in nature and reflect concerns about impaired efficiency and preference for native clinical judgement over that of electronic tools.

Moving forward, CDS, perhaps coupled with performance feedback, seems to offer the best hope of reducing inappropriate CTPA use. The growing use of electronic medical records, which is accelerated in the United States by the meaningful use provisions of the Health Information Technology for Economic and Clinical Health Act of 2009, implies that CDS tools are going to be implemented across the spectrum of diagnoses, including that of PE. ${ }^{13}$ The goals of CDS interventions, namely improved patient safety, quality, and cost-effectiveness, are more likely to be achieved if those studying and designing these electronic tools understand the day-to-day practice of clinical medicine. As summarized by Bates and colleagues ${ }^{14}$ in the "Ten Commandments for Effective Clinical Decision Support," CDS interventions will be successful in changing physician behavior and promoting the right test or treatment only if they seamlessly fit into the clinical workflow, have no impact on (or improve upon) physician efficiency, and minimize the need for additional information from the user. As suggested by Deblois et al., ${ }^{12}$ future studies of CDS interventions that aim to align CTPA use with recommended best practices should incorporate more rigorous methodological quality, include safety and cost-effectiveness outcomes, and, perhaps most 
importantly, attempt to understand the environmental and organizational factors that contribute to CDS tool effectiveness.

Disclosure: The authors have declared no conflicts of interest.

\section{References}

1. Kocher KE, Meurer WJ, Fazel R, Scott PA, Krumholz HM, Nallamothu BK. National trends in use of computed tomography in the emergency department. Ann Emerg Med. 2011;58(5):452-462.

2. Smith SB, Geske JB, Kathuria P, et al. Analysis of National Trends in Admissions for Pulmonary Embolism. Chest. 2016;150(1):35-45.

3. Wiener RS, Schwartz LM, Woloshin S. Time trends in pulmonary embolism in the United States: evidence of overdiagnosis. Arch Intern Med. 2011;171(9):831-837.

4. Wiener RS, Schwartz LM, Woloshin S. When a test is too good: how CT pulmonary angiograms find pulmonary emboli that do not need to be found. BMJ. 2013;347:f3368.

5. Kearon C, Akl EA, Ornelas J, et al. Antithrombotic Therapy for VTE Disease: CHEST Guideline and Expert Panel Report. Chest. 2016;149(2):315-352.

6. Sarma A, Heilbrun ME, Conner KE, Stevens SM, Woller SC, Elliott CG. Radiation and chest CT scan examinations: what do we know? Chest. 2012;142(3):750-760.
7. Fanikos J, Rao A, Seger AC, Carter D, Piazza G, Goldhaber SZ. Hospital costs of acute pulmonary embolism. Am J Med. 2013;126(2):127-132.

8. Raja AS, Greenberg JO, Qaseem A, et al. Evaluation of Patients With Suspected Acute Pulmonary Embolism: Best Practice Advice From the Clinical Guidelines Committee of the American College of Physicians. Ann Intern Med. 2015;163(9):701-711.

9. Schuur JD, Carney DP, Lyn ET, et al. A top-five list for emergency medicine: a pilot project to improve the value of emergency care. JAMA Intern Med. 2014;174(4):509-515.

10. Alhassan S, Sayf AA, Arsene C, Krayem H. Suboptimal implementation of diagnostic algorithms and overuse of computed tomography-pulmonary angiography in patients with suspected pulmonary embolism. Ann Thorac Med. 2016;11(4):254-260.

11. Crichlow A, Cuker A, Mills AM. Overuse of computed tomography pulmonary angiography in the evaluation of patients with suspected pulmonary embolism in the emergency department. Acad Emerg Med. 2012;19(11):1219-1226.

12. Deblois S, Chartrand-Lefebvre C, Toporwicz K, Zhongyi C, Lepanto L. Interventions to reduce the overuse of imaging for pulmonary embolism: a systematic review. J Hosp Med. 2018;13(1):52-61.

13. Murphy EV. Clinical decision support: effectiveness in improving quality processes and clinical outcomes and factors that may influence success. Yale J Biol Med. 2014;87(2):187-197.

14. Bates DW, Kuperman GJ, Wang S, et al. Ten commandments for effective clinical decision support: making the practice of evidence-based medicine a reality. J Am Med Inform Assoc. 2003;10(6):523-530. 